\title{
Frontières
}

\section{RELATIONS, Sur les traces de la mort, numéro 696, novembre 2004}

\section{Jean-Jacques Lavoie}

Volume 17, numéro 1, automne 2004

URI : https://id.erudit.org/iderudit/1073619ar

DOI : https://doi.org/10.7202/1073619ar

Aller au sommaire du numéro

Éditeur(s)

Université du Québec à Montréal

ISSN

1180-3479 (imprimé)

1916-0976 (numérique)

Découvrir la revue

Citer ce compte rendu

Lavoie, J.-J. (2004). Compte rendu de [RELATIONS, Sur les traces de la mort, numéro 696, novembre 2004]. Frontières, 17(1), 98-98.

https://doi.org/10.7202/1073619ar

Ce document est protégé par la loi sur le droit d'auteur. L'utilisation des services d'Érudit (y compris la reproduction) est assujettie à sa politique d'utilisation que vous pouvez consulter en ligne.

https://apropos.erudit.org/fr/usagers/politique-dutilisation/
Cet article est diffusé et préservé par Érudit.

Érudit est un consortium interuniversitaire sans but lucratif composé de l’Université de Montréal, l'Université Laval et l'Université du Québec à Montréal. Il a pour mission la promotion et la valorisation de la recherche. https://www.erudit.org/fr/ 
pas capables» (p. 23). À mon avis, comme l'être humain ne peut vivre avec la pensée constante de la fin, le problème de la société contemporaine est peut être moins celui du déni ou du non-déni de la mort que celui de la privatisation des rites et de ses conséquences sur la façon dont les êtres humains font face à la mort. Or tel est l'un des sujets traités par Sébastien St-Onge qui s'interroge sur l'évolution de l'industrie funéraire au Québec. Dans des textes un peu plus brefs mais non moins pertinents, Marco Veilleux, Guy Paiement et Gregory Baum proposent quelques réflexions critiques sur la vie et la mort à la lumière de la foi en la résurrection du Christ. Enfin, deux textes et plusieurs peintures d'Ozanne Tremblay, "décédée en 1997 à la suite d'un rude combat contre la maladie» (p. 10),

REVUE RELATIONS

\section{Sur les traces de la mort}

Numéro 696, novembre 2004

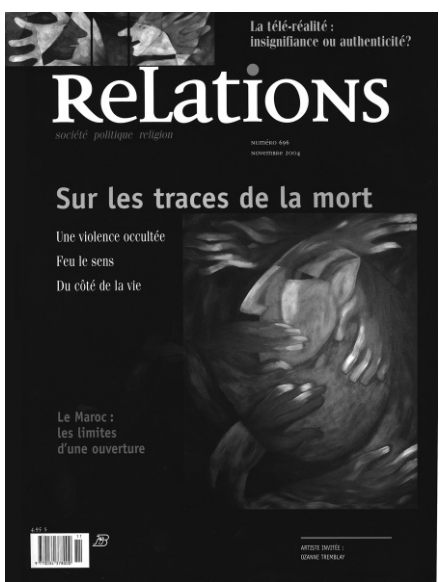

Peut-on parler de la mort? Certes, mais jamais comme d'un objet que l'on peut saisir, car la mort reste impensable. C'est pourquoi les ouvrages qui traitent de la mort devisent de choses et d'autres et surtout d'autre chose. Tel est également le cas de la revue Relations, publiée par le Centre justice et foi, qui propose dans son numéro du mois de novembre 2004 un dossier intitulé "Sur les traces de la mort» (p. 10 à 25). Les diverses voies qu'emprunte le déni de la mort dans la société actuelle est le premier thème abordé. L'article est signé par Luce Des Aulniers. Pour sa part, dans sa méditation philosophique et poétique sur la vie, la mort et le temps, Marc Chabot ne croit pas que nous soyons en train de fuir et de banaliser la mort. Au contraire, la mort «est un fait permanent de l'univers, nous ne voudrions pas y penser que nous n'en serions accompagnent ce dossier et permettent de prolonger la réflexion sur tout ce qu'il y a de pensable dans l'impensable de la mort.

En résumé, ce petit dossier, introduit par la rédactrice en chef Anne-Marie Aitken, est à la fois dense, clair et critique; c'est pourquoi il mérite d'être connu par un très large public.

Jean-Jacques Lavoie 